\title{
Base-accelerated degradation of nanosized platinum electrocatalysts
} Hersbach, T.J.P.; Garcia, A.C.; Kroll, T.; Sokaras, D.; Koper, M.T.M.; Garcia-Esparza, A.T.

\section{Citation}

Hersbach, T. J. P., Garcia, A. C., Kroll, T., Sokaras, D., Koper, M. T. M., \& Garcia-Esparza, A. T. (2021). Base-accelerated degradation of nanosized platinum electrocatalysts. Acs Catalysis, 11(15), 9904-9915. doi:10.1021/acscatal.1c02468

Version: $\quad$ Publisher's Version

License: $\quad$ Licensed under Article 25fa Copyright Act/Law (Amendment Taverne)

Downloaded from: https://hdl.handle.net/1887/3248543

Note: To cite this publication please use the final published version (if applicable). 


\title{
Base-Accelerated Degradation of Nanosized Platinum Electrocatalysts
}

\author{
Thomas J. P. Hersbach, ${ }^{\nabla}$ Amanda C. Garcia, Thomas Kroll, Dimosthenis Sokaras, Marc T. M. Koper,* \\ and Angel T. Garcia-Esparza*,
}

Cite This: ACS Catal. 2021, 11, 9904-9915

Read Online

\section{ACCESS | Llll Metrics \& More | 回 Article Recommendations | (s) Supporting Information}

ABSTRACT: In the pursuit of a hydrogen economy, extensive research has been directed at developing acidic and alkaline hydrogen fuel cells. Such fuel cells often utilize platinum-based catalysts. These materials have been studied extensively in acidic conditions but not in alkaline ones. This focus on acidic systems creates a marked knowledge gap, since recent studies indicate that carbon-supported platinum (Pt/C) electrocatalysts degrade more rapidly in bases than in acids. Addressing this gap, the present work investigates $\mathrm{Pt} / \mathrm{C}$ degradation at $\mathrm{pH} 2$ and $\mathrm{pH} 12$ using electrochemistry, transmission electron microscopy (TEM), and in situ X-ray absorption spectroscopy (XAS). TEM and XAS reveal accelerated $\mathrm{Pt} / \mathrm{C}$ degradation at high $\mathrm{pH}$ levels, which results in

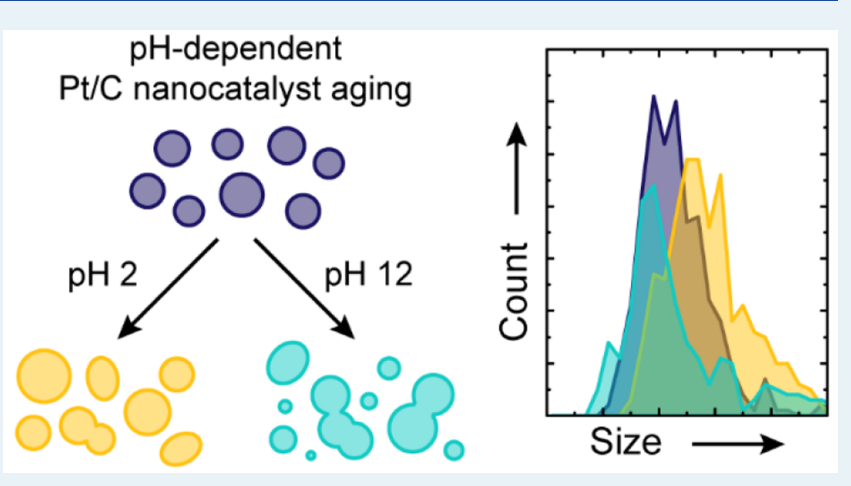
increased Ostwald ripening, Smoluchowski agglomeration, and nanoparticle detachment. These processes are driven by platinum-catalyzed carbon corrosion and the dissolution and redeposition of platinum nanoparticles. Although these processes take place at both low and high $\mathrm{pH}$ levels, basic conditions accelerate the degradation. Base-enhanced Pt dissolution and redeposition was assessed in further detail, revealing an oxidation onset reduction of $100 \mathrm{mV}$ in the base; however, there were no significant differences between undissolved Pt oxidation in acid and in base. The results suggest that soluble Pt oxidation products are stabilized in the base instead. These conclusions are important for translating acidbased literature to alkaline conditions.

KEYWORDS: fuel cells, electrocatalysis, corrosion, catalyst aging, hydrogen economy

\section{INTRODUCTION}

In an effort to mitigate climate change, governments are stimulating the substitution of fossil fuels with "green" electricity-derived hydrogen. ${ }^{1}$ Hydrogen would be used to heat homes, power vehicles, and store renewable energy, thus creating a hydrogen economy. ${ }^{2}$ Such a hydrogen economy was already conceived of in the early 1970 s, ${ }^{3}$ but it is only now nearing economic viability. ${ }^{4}$ Facilitating a universally implemented hydrogen economy requires significant cost reductions for green hydrogen production, transportation, storage, and consumption. ${ }^{1,2}$

Affordably producing and utilizing green hydrogen requires efficient electrolyzers and fuel cells. Such devices have lifetimes of tens of thousands of hours, demanding catalysts that are stable for an equally long period. ${ }^{5,6}$ Crucially, ensuring catalyst longevity requires a detailed understanding of the degradation mechanisms. This philosophy has spurred extensive research efforts in mapping the aging of platinum-based catalysts because Pt-containing electrodes enable most state-of-the-art fuel cells and electrolyzers. ${ }^{6-8}$

$\mathrm{Pt}$ aging studies have identified the species that form when platinum is oxidized in acidic electrolytes. Though multiple oxidized Pt species can coexist at a given potential, ${ }^{9-11}$ it is generally accepted that $\mathrm{Pt}$ initially oxidizes to $\mathrm{PtOH} .^{7}$ This species attains near-monolayer surface coverage between 1.0 and $1.1 \mathrm{~V}$ vs the reversible hydrogen electrode (RHE)., ${ }^{92-16}$ $\mathrm{Pt}-\mathrm{OH}$ subsequently oxidizes to $\mathrm{PtO}^{9,14}$ and mainly forms $\alpha$ $\mathrm{PtO}_{2}$ above $\sim 1.3 \mathrm{~V}$ vs RHE. ${ }^{10,14,15}$ Following $\alpha-\mathrm{PtO}_{2}$ formation, a variety of $\mathrm{Pt}$ oxides can form at higher oxidation potentials and longer polarization times. ${ }^{14,17-19}$

Regardless of the composition of the $\mathrm{Pt}$ oxide, modest amounts of Pt dissolve when Pt electrodes are held at voltages above $0.85 \mathrm{~V}$ vs RHE through so-called "steady-state" dissolution. $^{20}$ More extensive dissolution occurs when $\mathrm{Pt}$ oxides are reduced back to their metallic state. ${ }^{20-22}$ Because such dissolution occurs in the short time interval of Pt oxide reduction, it is referred to as "transient dissolution".

Received: June 2, 2021

Revised: July 4, 2021

Published: July 23, 2021 
Transient dissolution presumably occurs via the formation of soluble $\mathrm{Pt}$ (II) species, ${ }^{23}$ which can either be redeposited onto the native $\mathrm{Pt}$ electrode or diffuse into the working electrolyte. $^{24,25}$

Although the understanding of transient and steady-state degradation is extensive for Pt in acidic electrolytes, such knowledge is far less comprehensive in alkaline media. ${ }^{26}$ This difference is underscored by recent work indicating that acidbased literature does not necessarily translate to Pt in a base: at high $\mathrm{pH}$ levels, bulk $\mathrm{Pt}$ experiences more transient dissolution than at that at low $\mathrm{pH}$ levels. ${ }^{24,25,27,28}$ Additionally, carbonsupported platinum $(\mathrm{Pt} / \mathrm{C})$ nanoparticles suffer increased $\mathrm{Pt}$ catalyzed corrosion of the carbon support in base. ${ }^{29,30}$ Understanding these degradation processes in base is essential because $\mathrm{Pt} / \mathrm{C}$ particles are used in large-scale anion-exchange fuel cells that operate under alkaline conditions. ${ }^{26}$ Therefore, there is a significant need for studies of Pt catalysts over a wide range of $\mathrm{pH}$ values. ${ }^{7,26,31,32}$

The present work addresses $\mathrm{Pt} / \mathrm{C}$ nanoparticle aging in acidic and alkaline electrolytes. The work combines electrochemical characterization, ex situ transmission electron microscopy (TEM), and in situ high-energy resolution fluorescence detection X-ray absorption near-edge structure (HERFD-XANES) spectroscopy. Although the electrochemical results suggest minor differences between the nanoparticle degradation in acid and base, the TEM and HERFD-XANES results point toward strongly accelerated growth and agglomeration in alkaline solutions. This acceleration is attributed to an enhancement of both the carbon corrosion and the diffusion of dissolved $\mathrm{Pt}$ species in alkaline media. These results indicate the importance of a combination of $e x$ situ and in situ characterizations of catalysts when quantifying aging. Importantly, our work provides crucial input for the development of technologies to enable the hydrogen economy.

\section{MATERIALS AND METHODS}

Electrochemical Characterization. All water used in this study was purified using a Milli-Q Millipore system with a final total organic carbon content below $5 \mathrm{ppb}$ and a resistivity above $18.2 \mathrm{M} \Omega \cdot \mathrm{cm}$. Prior to the electrochemical characterization experiments, all glassware was kept in an aqueous solution of $1 \mathrm{~g} \cdot \mathrm{L}^{-1} \mathrm{KMnO}_{4}$ (Sigma-Aldrich, ACS reagent) and $0.5 \mathrm{M} \mathrm{H}_{2} \mathrm{SO}_{4}$ (Sigma-Aldrich, ACS reagent) overnight. This solution was drained on the day of the experiments, and a small amount of $\mathrm{H}_{2} \mathrm{O}_{2}$ (Merck, Emprove exp) was used to remove any remaining manganese species from the glassware. The glassware was subsequently boiled in Milli-Q water for $15 \mathrm{~min}$. This 15 min boil was repeated with fresh Milli-Q water until a total of five boiling cycles was reached.

Following cleaning, the electrochemical cell was filled with an aqueous working electrolyte, either $0.1 \mathrm{M} \mathrm{KClO}_{4}$ (SigmaAldrich, ACS reagent) with $0.01 \mathrm{M} \mathrm{HClO}_{4}$ (Sigma-Aldrich, ACS reagent) to achieve $\mathrm{pH} 2$ or $0.09 \mathrm{M} \mathrm{KClO}_{4}$ with $0.01 \mathrm{M}$ $\mathrm{KOH}$ (Fluka, TraceSelect) to achieve $\mathrm{pH}$ 12. The cell contained a glassy carbon (GC) counter electrode (Alfa Aesar, type $1, \varnothing=5 \mathrm{~mm}$, length of $100 \mathrm{~mm}$ ) and a HydroFlex reversible hydrogen reference electrode (Gaskatel). Prior to electrochemical experiments, the electrochemical cell was deaerated by purging Ar (Airgas, UHP grade) through the working electrolyte for at least $15 \mathrm{~min}$. During experiments, an oxygen-free environment was maintained by flowing Ar over the working solution. In the deaerated electrochemical cell, a GC electrode (Alfa Aesar, $\varnothing=5 \mathrm{~mm}$ ) was used as a working electrode onto which a small amount of Pt/C (PK Catalyst, 5 wt \% Pt) was applied. Prior to application, the $\mathrm{Pt} / \mathrm{C}$ was suspended at a concentration of $7 \mathrm{mg} \cdot \mathrm{mL}^{-1}(0.35 \mathrm{mg} \mathrm{Pt}$. $\mathrm{mL}^{-1}$ ) in a $40 / 60(\mathrm{v} / \mathrm{v})$ mixture of isopropanol (SigmaAldrich, for HPLC) and ethanol (Merck, Uvasol). This suspension was ultrasonicated for $1 \mathrm{~min}$, then $2.5 \mu \mathrm{L}$ of the solution was applied to the GC electrode and air-dried.

The working electrode was subjected to the following electrochemical protocol. First, the electrode surface was cleaned electrochemically by running 20 cyclic voltammograms (CVs) between 0.06 and $1.4 \mathrm{~V}$ vs RHE at a scan rate of 200 $\mathrm{mV} \cdot \mathrm{s}^{-1}$. Four additional $\mathrm{CV}$ cycles were performed between 0.06 and $0.7 \mathrm{~V}$ vs RHE at $50 \mathrm{mV} \cdot \mathrm{s}^{-1}$ to characterize the state of the $\mathrm{Pt}$ nanoparticle surface. Following cleaning and characterization, the Pt nanoparticles were held at $0.7 \mathrm{~V}$ vs RHE for one minute to oxidize them. The potential was then swept from the anodic holding potential to $0.06 \mathrm{~V}$ vs RHE at a $50 \mathrm{mV} \cdot \mathrm{s}^{-1} \mathrm{scan}$ rate to record the reduction charge of any oxidized $\mathrm{Pt}$ species. The $\mathrm{Pt}$ nanoparticles were then recharacterized by running five voltammetry cycles between 0.06 and $0.7 \mathrm{~V}$ vs RHE at $50 \mathrm{mV}$. $\mathrm{s}^{-1}$. This protocol of a 60-s oxidative hold, a subsequent reductive sweep, and voltammetric characterization was repeated at increasingly positive anodic hold potentials. At every iteration, the hold potential was increased by $0.1 \mathrm{~V}$ until a final hold potential of $1.4 \mathrm{~V}$ vs RHE was reached.

In this work, all currents and charges are normalized as current and charge densities. When normalizing, the hydrogen desorption charge before the first oxidative hold was used. A specific charge of $200 \mu \mathrm{C} \cdot \mathrm{cm}^{-1}$ was used for the voltammograms collected at $\mathrm{pH} 2$, whereas a specific charge of $145 \mu \mathrm{C}$. $\mathrm{cm}^{-1}$ was used for those collected at $\mathrm{pH} 12 .^{33}$

Electrochemical Characterization during In Situ HERFD-XANES Experiments. A custom-made electrochemical cell was used for in situ X-ray spectroscopy experiments. ${ }^{34}$ Specifically, the cell was comprised of a $4.5 \mathrm{~mL}$ cuvette (American Scientific Products, polystyrene) in which a $5 \mathrm{~mm}$ diameter hole was drilled to accommodate the working electrode. This electrode consisted of a $20 \mathrm{~nm}$ thick Au layer that was sputtered on top of a $5 \mathrm{~nm}$ thick $\mathrm{Cr}$ adhesion layer on a $1 \mu \mathrm{m}$ thick silicon nitride window (Norcada). This window was encased in a $1 \mathrm{~cm} \times 1 \mathrm{~cm}$ frame. On top of the window and the frame, $20 \mu \mathrm{L}$ of the $\mathrm{Pt} / \mathrm{C}$ suspension was drop-casted and dried under a He stream, thus achieving a Pt loading of 7 $\mu \mathrm{g} \cdot \mathrm{cm}^{-2}$. This catalyst layer did not contain an ionomer. After applying the $\mathrm{Pt} / \mathrm{C}$ suspension, the working electrode was affixed to the electrochemical cell using Torr Seal (Varian Inc.). The cell was then filled with $3 \mathrm{~mL}$ of the $\mathrm{pH} 2$ or $\mathrm{pH} 12$ solution (see the Electrochemical Characterization subsection). This setup used a Pt wire as the counter electrode and a HydroFlex reversible hydrogen reference electrode (Gaskatel). During experiments, the working electrolyte was continuously purged with Ar gas (Airgas, UHP grade) to maintain oxygenfree conditions.

After mounting the electrochemical XAS cell, the working electrode was electrochemically cleaned by cycling between 0 and $1.4 \mathrm{~V}$ vs RHE 20 times at a scan rate of $250 \mathrm{mV} \cdot \mathrm{s}^{-1}$. Four subsequent voltammetry cycles were performed between 0.06 and $0.7 \mathrm{~V}$ vs RHE at a scan rate of $50 \mathrm{mV} \cdot \mathrm{s}^{-1}$ as well as a final cycle between 0.06 and $1.4 \mathrm{~V}$ vs RHE. After acquiring these cleaning and surface characterization CVs, the electrode was held at various potentials in order to acquire steady-state HERFD-XANES spectra. 

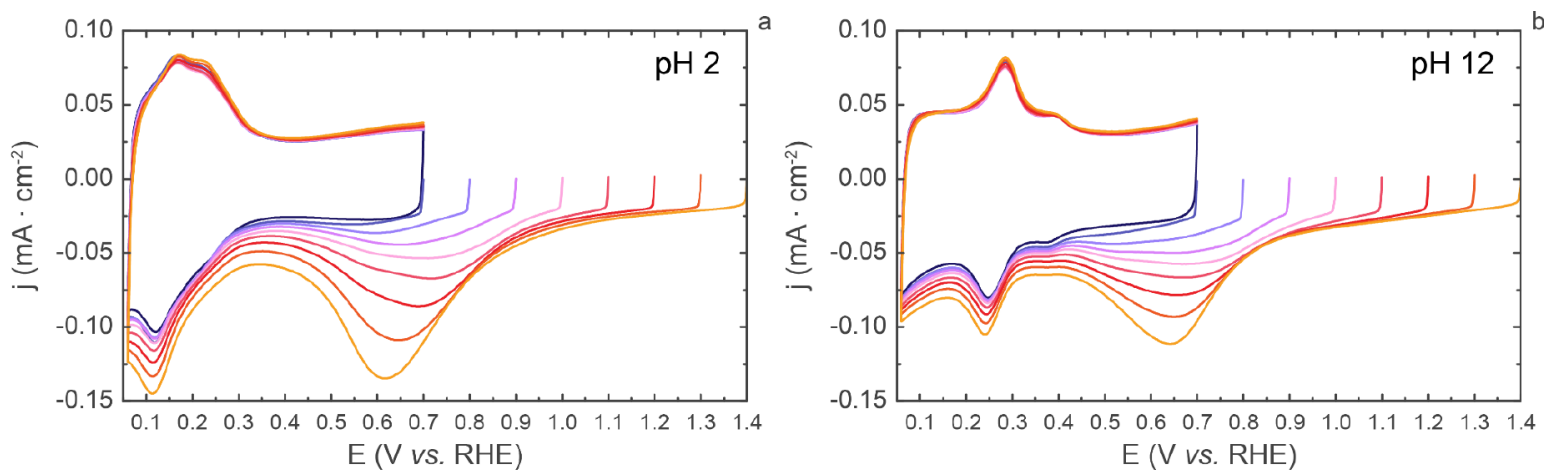

— Before oxidative holds Other traces: after 1-minute oxidative hold

Figure 1. Cyclic voltammograms before and after one-minute holds at various oxidative potentials in (a) $\mathrm{pH} 2$ and (b) $\mathrm{pH} 12$. Electrolytes used were as follows: (a) $100 \mathrm{mM} \mathrm{KClO}_{4}$ plus $10 \mathrm{mM} \mathrm{HClO}_{4}$ and (b) $90 \mathrm{mM} \mathrm{KClO}_{4}$ plus $10 \mathrm{mM} \mathrm{KOH}$. Scan rate was $50 \mathrm{mV} \cdot \mathrm{s}^{-1}$.

In Situ HERFD-XANES Experiments. HERFD-XANES experiments were performed at beamline 6-2b of the Stanford Synchrotron Radiation Lightsource. A double-crystal Si(311) monochromator was used to select the energy of the X-ray beam. A Rh-coated parabolic mirror was used to reject higher harmonics and focus the beam on the sample, with a full width at half-maximum of approximately $420 \mu \mathrm{m}$ (horizontally) by $130 \mu \mathrm{m}$ (vertically). Prior to the experiments, the beam energy was calibrated with respect to a metallic Pt foil for which a value of $11563.7 \mathrm{eV}$ was assigned to the first inflection point of the Pt $\mathrm{L}_{\mathrm{III}}$ edge XAS spectrum. During experiments, fluorescent $\mathrm{X}$-rays were detected by a Johann-type X-ray spectrometer. ${ }^{35}$ The spectrometer used five $\mathrm{Ge}(660)$ spherically bent analyzers ( $1 \mathrm{~m}$ radius of curvature) in order to selectively detect the fluorescent Pt $\mathrm{L}_{\alpha 1} \mathrm{X}$-rays (energy of $9442 \mathrm{eV}$ ) with an energy resolution of $1.0 \mathrm{eV}$. When compared to conventional XAS modes, the energy resolution of the adopted HERFD-XANES provides two critical advantages: a suppression of the intermediate-state lifetime that results in more pronounced spectral fingerprints ${ }^{36}$ and a complete rejection of the scattering background, which dramatically enhances the detection sensitivity.

XANES Data Processing. The collected HERFD-XANES spectra were aligned in the energy axis using a monochromator glitch feature. These aligned spectra were averaged in the ATHENA software ${ }^{37}$ and subsequently flattened and normalized by setting the edge jump to one. This normalization was emphasized by plotting all X-ray absorption spectra in $y$-axis units of "edge fraction". 38

Transmission Electron Microscopy. Transmission electron microscopy was used to analyze the as-received $\mathrm{Pt} / \mathrm{C}$ and the $\mathrm{Pt} / \mathrm{C}$ that underwent various amounts of degradation. These aged samples are labeled as "CV treatment", "1.4 V hold", and "extensively aged". The "CV treatment" sample was cycled between 0 and $1.4 \mathrm{~V}$ vs RHE 20 times at a scan rate of $250 \mathrm{mV} \cdot \mathrm{s}^{-1}$, followed by four voltammetry cycles at $50 \mathrm{mV} \cdot \mathrm{s}^{-1}$ between 0.06 and $0.7 \mathrm{~V}$ vs RHE, two cycles at $50 \mathrm{mV} \cdot \mathrm{s}^{-1}$ between 0.06 and $1.4 \mathrm{~V}$ vs RHE, and two final cycles between 0 and $1.4 \mathrm{~V}$ vs RHE. The "1.4 V hold" samples underwent the same procedure as the "CV treatment" samples and were then polarized at 0.4 and $1.4 \mathrm{~V}$ vs RHE for 20 min each. Finally, the "extensively aged" sample underwent the same treatment as the "1.4 V hold" sample, followed by successive polarization at 0.0 , $0.6,0.3,0.0,0.4,0.7,0.8,0.9,1.0,1.1,1.2,1.3$, and $1.4 \mathrm{~V}$ vs
RHE for $20 \mathrm{~min}$ each. These potentials match the potential sequence that was used during HERFD-XANES experiments.

Following electrochemistry, the nanoparticle suspension was removed from the glassy carbon working electrode by briefly sonicating the electrode in a mixture of $0.5 \mathrm{~mL}$ of water and $0.5 \mathrm{~mL}$ of isopropanol. Then, $5 \mu \mathrm{L}$ of this mixture was dropcasted onto a TEM grid (Electron Microscopy Sciences, carbon film on 400 mesh copper) and vacuum-dried. Samples were imaged on an FEI Tecnai transmission electron microscope using an acceleration voltage of $200 \mathrm{kV}$. The acquired images were used to construct particle-size distributions by analyzing 200 nanoparticles per sample. Particles were sized by tracing their contours in Image $J$ and measuring the Feret diameter of the traced particles. If particles had aggregated, the entire aggregate was sized as one particle. Particle sizes are reported as median sizes with single standard deviations. Representative TEM images are displayed in Figure $\mathrm{S} 1$ for as-received particles, Figure $\mathrm{S} 2$ for particles aged at $\mathrm{pH}$ 2, and in Figure S3 for particles aged at $\mathrm{pH} 12$.

\section{RESULTS}

In studying $\mathrm{pH}$-dependent $\mathrm{Pt} / \mathrm{C}$ degradation, this work focuses on $\mathrm{pH} 2$ and $\mathrm{pH} 12$. These $\mathrm{pH}$ values were obtained by adding either $\mathrm{HClO}_{4}$ or $\mathrm{KOH}$ to a $\mathrm{KClO}_{4}$ supporting electrolyte. This $\mathrm{KClO}_{4}$-based supporting electrolyte was chosen to match the general electrolyte conditions between $\mathrm{pH}$ values while minimizing the surface adsorption of electrolyte ions. However, note that completely eliminating electrolyte-surface interactions is not achievable due to $\mathrm{ClO}_{4}{ }^{-}$interacting with adsorbed $* \mathrm{OH}$ in acidic conditions ${ }^{15,39}$ and $\mathrm{K}^{+}$interacting with adsorbed $* \mathrm{H}_{2} \mathrm{O}$ or $* \mathrm{OH}$ in alkaline conditions. ${ }^{40-42}$ In both acidic and alkaline conditions, $\mathrm{Pt} / \mathrm{C}$ degradation was studied through electrochemistry, ex situ TEM, and in situ HERFDXANES. The results of these studies will be presented in the following subsections.

Electrochemical Oxidation and Reduction. Figure 1 displays surface-normalized voltammograms that illustrate $\mathrm{Pt}$ oxidation and reduction in acidic and alkaline conditions. These processes were probed electrochemically by holding the working electrode at a given oxidative potential for one minute. Following this positive hold, the working electrode was swept to $0.06 \mathrm{~V}$ vs RHE in order to reduce the Pt surface, which produced a reduction peak between 0.4 and $1.0 \mathrm{~V}$ vs RHE. Five more cyclic voltammograms were performed between 0.06 and $0.7 \mathrm{~V}$ vs RHE to recharacterize the $\mathrm{Pt} / \mathrm{C}$ surface 
through the hydrogen adsorption and desorption features that are visible below $0.4 \mathrm{~V}$ vs RHE. ${ }^{33}$ After recharacterizing the surface, the next oxidative hold was performed. This procedure was repeated until the Pt surface was held at $1.4 \mathrm{~V}$ vs RHE and then subsequently reduced through a final negative-going voltammetric sweep. In Figure 1, the absolute hydrogen desorption charge between 0.06 and $0.3 \mathrm{~V}$ vs RHE varies less than several percent between potential holds, suggesting that no significant amount of the surface area was created or lost during the electrochemical oxidation and reduction protocol.

Figure 1 also highlights other interesting characteristics of the $\mathrm{Pt}$ surface reduction. Interestingly, a reduction peak is already visible after mildly anodic polarization at $0.7 \mathrm{~V}$ vs RHE. Although this feature occurs in the potential window where the reduction of the carbon support occurs, ${ }^{43,44}$ the additional reductive current after a hold at $0.7 \mathrm{~V}$ vs RHE likely corresponds to $* \mathrm{OH}$, as a small amount of $* \mathrm{OH}$ adsorbs on Pt at $0.7 \mathrm{~V}$ vs RHE. ${ }^{15,45}$ This assertion will further be explored in the In Situ HERFD-XANES section. Notably, this Pt reduction peak between 0.4 and $1.0 \mathrm{~V}$ vs RHE grows in size with increasing anodic hold potentials and is actually composed of two peaks in both the acid and the base. This peak duality has been noted before in acid, ${ }^{11,12}$ with the earlier (more positive) reduction peak being assigned to $* \mathrm{OH}$ reduction and the later (more negative) peak corresponding to $* \mathrm{O}$ reduction. ${ }^{11}$ Precise peak positions for $* \mathrm{OH}$ and $* \mathrm{O}$ reduction cannot be assigned due to the peaks shifting with increasing oxidation potentials. Both the early $* \mathrm{OH}$ reduction feature and the peak duality are seen at $\mathrm{pH} 2$ and $\mathrm{pH} 12$. However, these reduction features appear both larger and sharper in $\mathrm{pH}$ 2. It is therefore instructive to quantitatively assess this Pt reduction and the oxidation that precedes it.

A quantitative assessment is presented in Figure 2, where the oxidative charge density from the one minute oxidative holds is presented in panel a. The oxidative charge density increased with the increasing potential and is similar in both the acid and the base until $1.0 \mathrm{~V}$ vs RHE. At higher potentials, more oxidative charge is passed in the acid. This trend is matched by the reductive charge density (Figure $2 \mathrm{~b}$ ), which is similar between electrolytes until $1.0 \mathrm{~V}$ vs RHE and diverges at higher voltages. This divergence might suggest a change in the dissolution mechanism above $1.0 \mathrm{~V}$ vs RHE; in acidic conditions, steady-state $\mathrm{Pt}$ dissolution outweighs transient dissolution below $1.0 \mathrm{~V}$ vs RHE and is less relevant above this potential. $^{20}$

$\mathrm{Pt}$ reduction and oxidation in $\mathrm{pH} 2$ and ph 12 is explored further in Figure 2c, which displays the charge conservation ratio. This ratio was obtained by dividing the reductive charge density in Figure $2 b$ by the oxidative charge density in Figure 2a. The thus-achieved ratio is less than one, indicating that the oxidative charge density is larger than the reductive charge density. This observation is consistent with previous literature in acidic conditions. ${ }^{12,46,47}$ The charge conservation ratio increases between 0.7 and $1.0 \mathrm{~V}$ vs RHE and then decreases up to $1.4 \mathrm{~V}$ vs RHE in both the acid and the base. Within experimental error, the charge conservation ratios in the acid and the base are similar in magnitude at more positive potentials (Figure 2c). The matched ratio between $\mathrm{pH} 2$ and $\mathrm{pH} 12$ demonstrates that the increased oxidative charge density in $\mathrm{pH} 2$ in Figure 2a is proportional to the increase in reduction in Figure $2 \mathrm{~b}$. Overall, a strong $\mathrm{pH}$-dependent difference in $\mathrm{Pt}$ oxidation and reduction is therefore not apparent from the charge density quantification in Figure 2.
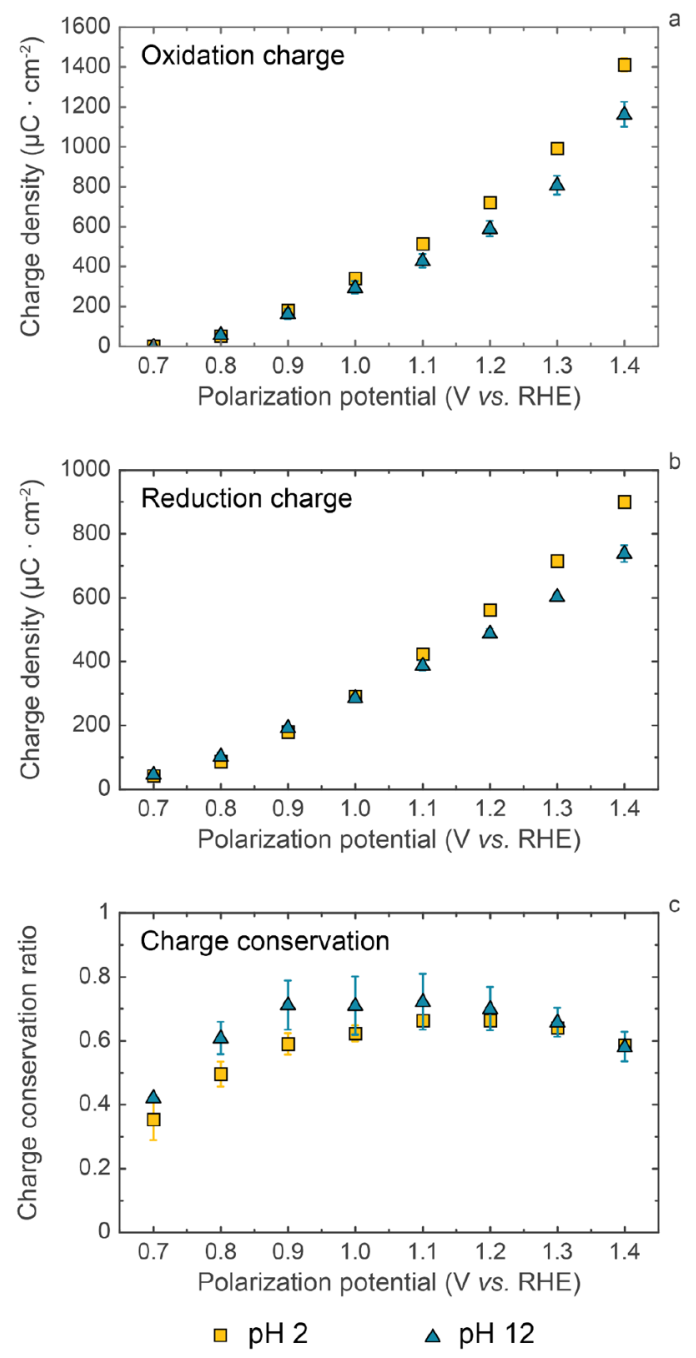

Figure 2. (a) Oxidative charge density during one minute oxidative holds, (b) reductive charge density after one minute oxidative holds, and (c) charge conservation. (a) Oxidative charge densities were determined by integrating the chronoamperometry current density during oxidation. (b) Reductive charge densities were determined by integrating the reductive voltammograms after one-minute oxidative holds. The negative integration limit was $0.4 \mathrm{~V}$, whereas the positive integration limit was the upper voltammetric potential bound. A horizontal baseline was used to compensate for the double layer current. (c) Charge conservation was determined as the ratio between the oxidative and reductive current densities. Each data point is the average of three experiments, and error bars represent one standard deviation.

Though the data in Figure 2 indicate only minor electrochemical $\mathrm{pH}$-dependent $\mathrm{Pt}$ oxidation and reduction differences, these data alone do not rule out differences in $\mathrm{Pt} /$ C catalyst degradation. Perhaps the most critical note regarding Figure 2 is that the charge conservation ratio does not correlate with the amount of $\mathrm{Pt}$ that is dissolved through oxidation and subsequently redeposited. This lack of a one-toone correlation between $\mathrm{Pt}$ charge conservation and $\mathrm{Pt}$ atom conservation is due to three reasons. First, part of the recorded charge could partially correspond to the oxidation of the carbon support instead of that singly from Pt. For example, it is known that $\mathrm{Pt}$ can electrochemically oxidize its carbon support to $\mathrm{CO}_{2} \cdot{ }^{48}$ Such an oxidation current will not correspond directly to Pt dissolution. Second, the presented Pt reduction 


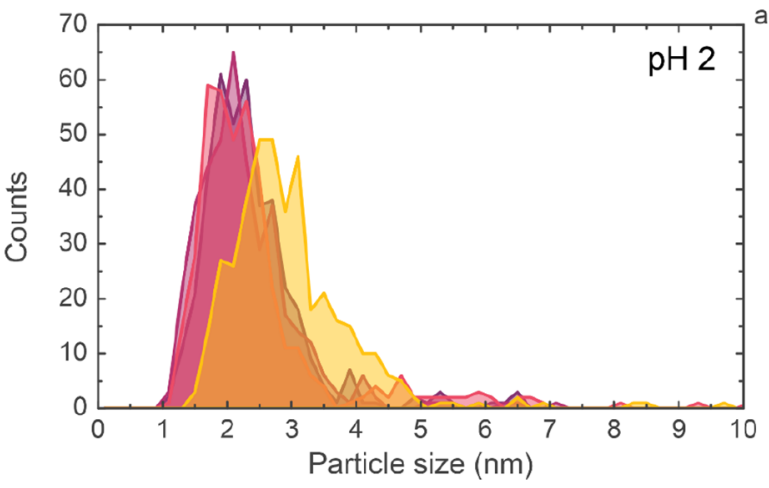

Ink

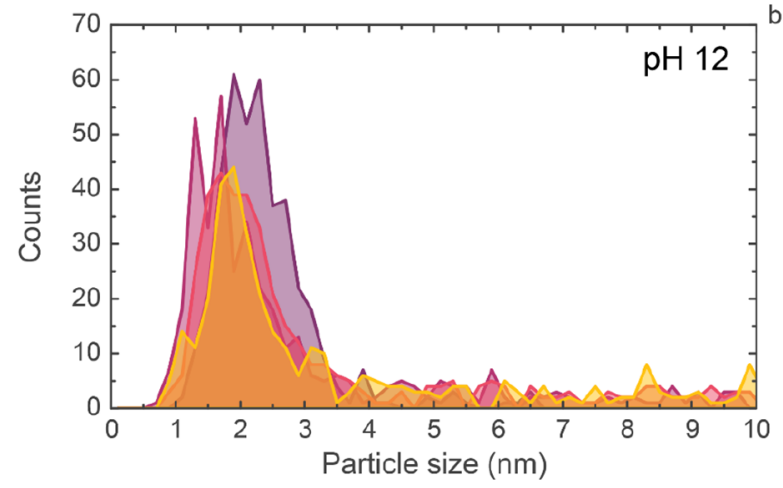

$1.4 \mathrm{~V}$ hold

\section{Extensively aged}

Figure 3. Particle size distributions of the as-received $\mathrm{Pt} / \mathrm{C}$ nanoparticle ink and those of the same nanoparticles after various electrochemical treatments in (a) $\mathrm{pH} 2$ and (b) $\mathrm{pH}$ 12. Each size distribution combines the results of two independent samples, accounting for 200 nanoparticles per sample (400 per distribution). Representative images for each sample are presented in the Supporting Information, including a version of panel b that extends to $30 \mathrm{~nm}$.

data (Figure $2 \mathrm{~b}$ ) were obtained with a lower charge integration limit of $0.4 \mathrm{~V}$ vs RHE. This integral therefore ignores the small amount of $\mathrm{Pt}$ oxide reduction that overlaps with hydrogen adsorption features (Figure 1) and is challenging to unambiguously background correct. Hence, ignoring this amount of $\mathrm{PtO}_{x}$ reduction will artificially diminish the calculated reduction charge in Figure $2 b$ and the charge conservation ratio in Figure 2c. Third, and perhaps most importantly, Pt reduction (Figure $2 \mathrm{~b}$ ) corresponds even more strongly to Pt dissolution than Pt oxidation does (Figure 2a), as significant amounts of $\mathrm{Pt}$ are dissolved during $\mathrm{PtO}_{x}$ reduction. $^{21}$

Notably, these three considerations underscore that the data in Figure 2 should not be taken as an indication that $\mathrm{Pt} / \mathrm{C}$ aging is near-identical in acidic and basic conditions. In fact, Figure 2 indicates that the similarity in acidic and alkaline electrochemistry can mask the well-documented $\mathrm{pH}$-dependent differences in $\mathrm{Pt} / \mathrm{C}$ degradation. ${ }^{24,25,27,29,30} \mathrm{~A}$ critical evaluation of Figure 2 therefore indicates a crucial need for complementary analysis techniques when studying $\mathrm{Pt} / \mathrm{C}$ aging. Such a complementary analysis is provided in the following sections through microscopy and spectroscopy.

Transmission Electron Microscopy. TEM is commonly utilized to visualize nanoparticle size distributions. Such size distributions are shown in Figure 3 for as-received $\mathrm{Pt} / \mathrm{C}$ nanoparticles as well as nanoparticles that underwent progressive amounts of degradation. The degraded samples were treated as described in the Transmission Electron Microscopy subsection of the Experimental section and are labeled "CV treatment", "1.4 V hold", and "extensively aged". The "CV treatment" protocol mimics the conditions that are typically used to electrochemically clean $\mathrm{Pt} / \mathrm{C}$ catalysts before experiments, ${ }^{23,49,50}$ or to stress-test such nanoparticles. ${ }^{48,49,51,52}$ The next sample set in Figure 3 is labeled "1.4 V hold" and identifies nanoparticle degradation after electrochemical cleaning and a single subsequent oxidative potential hold for $20 \mathrm{~min}$. The final degraded sample is labeled "extensively aged" and mimics degradation after a sequence of potential holds that might simulate start/stop catalytic conditions or varying fuel cell loads. ${ }^{53}$ Additionally, the "extensively aged" potentials match the potentials that were applied during HERFD-XANES data collection in this work.
Combined, the "extensively aged", "1.4 V hold", and "CV treatment" samples in Figure 3 represent a variety of protocols that are encountered in nanoparticle degradation studies.

Figure 3a shows a narrow size distribution for the asreceived $\mathrm{Pt} / \mathrm{C}$ nanoparticle ink, which has a mean particle size of $2.2 \pm 0.5 \mathrm{~nm}$. After the CV treatment in acid, the mean particle size remains similar at $2.1 \pm 0.6 \mathrm{~nm}$. This lack of severe nanoparticle growth after cycling in acid matches previous work. ${ }^{54}$ Further aging at $1.4 \mathrm{~V}$ vs RHE broadens the nanoparticle size distribution, yielding particles with a mean particle size of $2.3 \pm 1.0 \mathrm{~nm}$. Notably, both the $1.4 \mathrm{~V}$ hold and the $\mathrm{CV}$ treatment leave the main particle size feature relatively intact, as is indicated by a shift of the median particle size from 2.1 (ink) to 2.1 ( $\mathrm{CV}$ treatment) and $2.0 \mathrm{~nm}$ (1.4 V hold). More pronounced aggregation is visible after extensive aging, which pushes the mean particle size to $2.8 \pm 0.8 \mathrm{~nm}(2.6 \mathrm{~nm}$ median). Overall, the $0.6-\mathrm{nm}$ mean nanoparticle size shift between the ink and extensive aging remains relatively mild in acid conditions.

In contrast, pronounced degradation is visible at $\mathrm{pH} \mathrm{12}$, as the $\mathrm{CV}$ treatment yields a mean particle size of $3.4 \pm 3.0 \mathrm{~nm}$ ( $2.3 \mathrm{~nm}$ median size). Notably, the size distribution after the $\mathrm{CV}$ treatment contains $\sim 7 \%$ of nanoparticles in the $0.9-1.1$ $\mathrm{nm}$ range, which are not present in fractions above $1 \%$ in either the as-received nanoparticle ink or that after degradation in acid. Additionally, particle agglomerates as large as $20 \mathrm{~nm}$ are present. These agglomerates appear to be responsible for skewing the mean particle size $(3.4 \mathrm{~nm})$ away from the median size $(2.3 \mathrm{~nm})$. The large particles are visible in the micrographs in Figure S3, and the full-range particle size distribution is shown in Figure S4. Both these large agglomerates and the smaller $0.9-1.1 \mathrm{~nm}$ particles are also present after the hold at $1.4 \mathrm{~V}$ vs RHE for which a mean particle size of $3.8 \pm 4.0 \mathrm{~nm}$ and a median size of $2.1 \mathrm{~nm}$ were obtained. Finally, extensive aging generates a broad size distribution with a mean size of $5.5 \pm 4.9 \mathrm{~nm}$ (3.4 nm median).

The above results indicate that $\mathrm{Pt} / \mathrm{C}$ degradation in $\mathrm{pH} 12$ is more severe than that in $\mathrm{pH}$ 2. This is explicitly apparent when overlaying the particle size distributions after an identical treatment at low and high $\mathrm{pH}$ levels (Figure S5). The presently observed base-accelerated degradation is consistent with the literature; acidic electrolytes promote relatively mild nano- 

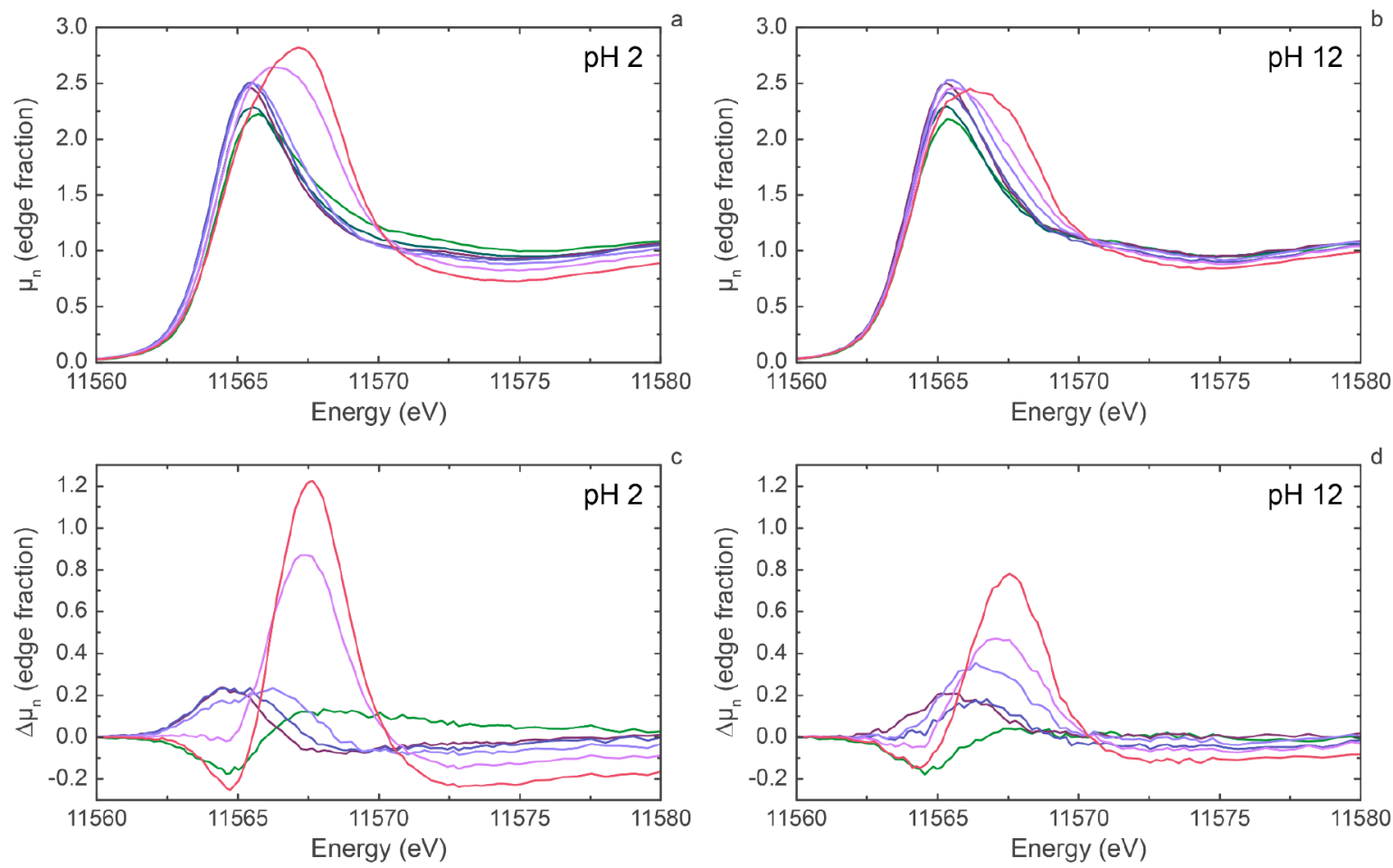

- O V vs. RHE

- 0.4 V vs. RHE

- 0.7 V vs. RHE

0.9 V vs. RHE

1.0 V vs. RHE

- 1.2 V vs. RHE

$1.4 \mathrm{~V} v$ s. RHE

Figure 4. ( $a$ and $b$ ) Pt $\mathrm{L}_{\mathrm{III}}$-edge HERFD-XANES spectra and ( $\mathrm{c}$ and $\mathrm{d}$ ) difference spectra of $\mathrm{Pt} / \mathrm{C}$ nanoparticles at various potential holds in (a and c) $\mathrm{pH} 2$ and(b and d) $\mathrm{pH} 12$ electrolytes. In order to construct difference spectra for a given sample, the in situ spectrum of the same sample at 0.4 $\mathrm{V}$ vs RHE was used as a reference spectrum.

particle growth, ${ }^{29,54}$ while alkaline electrolytes induce severe growth that is dominated by particle aggregation. ${ }^{29}$ Overall, the significant $\mathrm{pH}$-dependent differences warrant the further spectroscopic investigation of the studied $\mathrm{Pt} / \mathrm{C}$ catalysts.

In Situ HERFD-XANES. In-situ HERFD-XAS spectra of Pt/ $\mathrm{C}$ in $\mathrm{pH} 2$ and $\mathrm{pH} 12$ are presented in panels $\mathrm{a}$ and $\mathrm{b}$, respectively, of Figure 4. The same figure also contains difference spectra for $\mathrm{pH} 2$ and $\mathrm{pH} 12$ in panels $\mathrm{c}$ and $\mathrm{d}$, respectively. These difference spectra were obtained by subtracting the spectrum at $0.4 \mathrm{~V}$ vs RHE in panels a and $b$ from the other spectra in the respective panels. This differencebased procedure highlights small spectral changes ${ }^{55}$ and can be used to identify adsorbates on Pt (electro) catalysts. ${ }^{45,56-59}$ More specifically, the shape of a difference spectrum indicates the type of adsorbate, whereas the magnitude of a difference spectra indicates the relative abundances of these adsorbates. ${ }^{55}$ Including difference spectra in Figure 4 therefore helps highlight subtle chemical changes in the $\mathrm{Pt} / \mathrm{C}$ catalysts.

In $\mathrm{pH} 2$, the $\mathrm{Pt} / \mathrm{C}$ catalyst is in its metallic state at $0.4 \mathrm{~V}$ vs RHE; it is not covered by hydrogen, but a finite amount of adsorbed $* \mathrm{OH}$ is likely present at the top of Pt step edges and at corner sites. ${ }^{40,41,53,60}$ This $* \mathrm{OH}$ is substituted by $* \mathrm{H}$ when the electrode is stepped down to $0 \mathrm{~V}$ vs RHE. Such ${ }^{*} \mathrm{H}$ adsorption broadens the HERFD-XANES spectrum in Figure $4 \mathrm{a}$, thus producing corresponding features in the difference spectrum (Figure 4c). i.e., a negative feature around 11564.7 $\mathrm{eV}$ and a positive shoulder that gradually decreases in magnitude above $11567.1 \mathrm{eV}$. These changes in the normal and difference spectra match those in previous work ${ }^{53,61}$ and correspond to ${ }^{*} \mathrm{H}$ that adsorbs in the "hollow" position, ${ }^{56}$ as *H adsorption creates antibonding electronic states that broaden the XANES spectrum. ${ }^{62-64}$ Importantly, these hydrogen-induced changes are also visible at $\mathrm{pH} 12$ (Figure $4 \mathrm{~b}$ and $\mathrm{d}$ ); however, they are approximately fourfold smaller in magnitude than those in $\mathrm{pH} 2$. The decreased magnitude in the base is consistent with the TEM-observed particle growth at $\mathrm{pH} 12$ after the $\mathrm{CV}$ cleaning treatment (Figure $3 \mathrm{~b}$ ), as these larger particles have a lower surface-to-bulk ratio than the smaller particles. Because of the reduced amount of surface atoms at $\mathrm{pH} \mathrm{12,} \mathrm{less} \mathrm{Pt}$ atoms are available for hydrogen adsorption and, consequently, smaller hydrogen features were observed for $\mathrm{pH} 12$ in Figure 4 via HERFD-XANES.

Analogously to the HERFD-XANES features caused by the cathodically adsorbed $* \mathrm{H}$, features corresponding to the anodically adsorbed oxygen species are similar in shape but different in magnitude in the acid and the base. In both electrolytes, the main absorption peak (the whiteline) increases in intensity when the electrode potential is stepped from 0.4 to $0.7 \mathrm{~V}$ vs RHE. This increase yields a peak in the difference spectrum at $11564.5 \mathrm{eV}$, which signifies $* \mathrm{OH}$ adsorption. ${ }^{45,53,55,57}$ This spectroscopic fingerprint of $* \mathrm{OH}$ confirms that the reductive current after oxidation at $0.7 \mathrm{~V}$ vs RHE in Figure 1 corresponds to $\mathrm{Pt}-\mathrm{OH}$ reduction. Signs of additional adsorbates appear when the working electrode is polarized at $0.9 \mathrm{~V}$ vs RHE and above, as the intensity of the whiteline increases and its position gradually shifts. These changes in the spectra match those of the difference spectra, where a negative peak at $11564.5 \mathrm{eV}$ and a positive peak at $11567.6 \mathrm{eV}$ gradually 

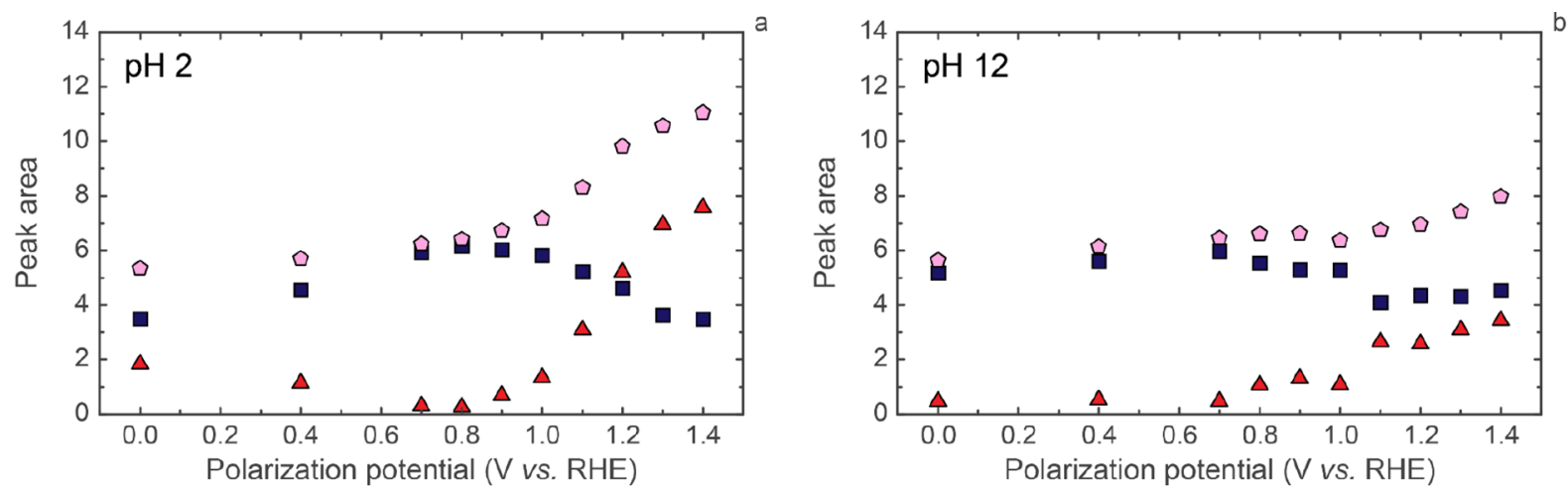

- Metal Peak

$\triangle$ Adsorbate Peak

- Peak Sum

Figure 5. Areas of the fitted metal peak, the adsorbate peak, and the sum of both peaks. Full fit results are given in the Supporting Information.

develop. The positive difference peak corresponds to multifoldbound oxygen $^{57}$ and therefore suggests platinum oxide formation. The platinum oxide feature in the difference spectrum is more pronounced for $\mathrm{pH} 12$ than for $\mathrm{pH} 2$ when the difference spectra at $0.9 \mathrm{~V}$ vs RHE are compared. This suggests an earlier onset for Pt oxide formation in the base. The latter observation is supported by earlier reports of dissolved Pt with online ICP-MS ${ }^{27}$ and with early onset oxidation currents during voltammetry in a base. ${ }^{33}$ Oxidized $\mathrm{Pt}$ that does not dissolve remains on the surface as $\mathrm{Pt}$ oxides $\left(\mathrm{PtO}_{x}\right)$. The identities of these oxides appear to be similar between the acid and the base, which is indicated by the difference spectra in these electrolytes having similar shapes. ${ }^{55}$ At potentials above $1.4 \mathrm{~V}$ vs RHE, the most predominant oxide phase is likely $\mathrm{PtO}_{2}$ in both the acid and the base; the shape of the difference spectra in Figure 4 matches that of a $\mathrm{PtO}_{2} \cdot \mathrm{H}_{2} \mathrm{O}$ standard compound with a negative peak at $11564.4 \mathrm{eV}$ and a positive peak at $11567.6 \mathrm{eV}$ (Figure S6). Interestingly, in absolute terms the amount of $\mathrm{PtO}_{2}$ formed is largest in the acid because the difference spectrum magnitude at $1.4 \mathrm{~V}$ vs RHE is larger in the acid than in the base.

The degree of $\mathrm{Pt}$ oxidation is explicitly explored in Figure 5, which utilizes a HERFD-XANES fitting procedure to approximate the relative amount of metallic and oxidized $\mathrm{Pt}^{53,61}$ Full fitting details are provided in Supporting Information Figure S7. Briefly, a simplified model assumes a pseudo-Voigt peak at $11564.50 \mathrm{eV}$ that is used to quantify the amount of metallic $\mathrm{Pt}$, whereas a pseudo-Voigt peak at $11567.55 \mathrm{eV}$ accounts for the amount of adsorbate-covered Pt. The adsorbate peak corresponds to ${ }^{*} \mathrm{H}$-covered $\mathrm{Pt}$ at potentials below $0.4 \mathrm{~V}$ vs $\mathrm{RHE}, * \mathrm{O}(\mathrm{H})$-covered $\mathrm{Pt}$, and $\mathrm{Pt}$ oxides at higher potentials. The sum of the adsorbate peak and the metallic peak is also displayed in Figure 5. The peak sum correlates with the amount of empty $\mathrm{Pt} \mathrm{d}$-states and is therefore a measure of Pt oxidation, ${ }^{65}$ where a higher peak sum indicates more oxidation.

As Figure 5 demonstrates, the metal peak, the adsorbate peak, and the peak sum vary as a function of the electrode potential. When lowering the electrode potential from 0.4 to 0 $\mathrm{V}$ vs RHE, the adsorbate peak decreases, and the metal peak increases. As mentioned in the previous paragraph, these changes correspond to $* \mathrm{H}$ adsorption. ${ }^{53}$ Additionally, the peak sum decreases slightly when moving toward $0 \mathrm{~V}$ vs RHE, which suggests a more reduced $\mathrm{Pt}$ state upon hydrogen adsorption. These changes in the adsorbate and metal peaks are 3-4 times more pronounced at $\mathrm{pH} 2$ than at $\mathrm{pH} 12$. Analogously, the peak integrals at higher potentials vary more at low $\mathrm{pH}$ values than at high $\mathrm{pH}$ values; the adsorbate and sum peaks are higher in the acid than in the base, whereas the metal peak is lower. These changes indicate that a larger relative amount of $\mathrm{Pt}$ is oxidized at low $\mathrm{pH}$ values. However, as is also suggested by Figure 4, oxidation commences at lower potentials in the base, as the adsorbate peak starts growing at $0.8 \mathrm{~V}$ vs RHE in the base and at $0.9 \mathrm{~V}$ vs RHE in the acid. In short, the onset of Pt oxidation appears at $\sim 100 \mathrm{mV}$ lesspositive potentials in the base, but a larger fraction of $\mathrm{Pt}$ atoms ultimately oxidizes in the acid at the highest potential.

\section{DISCUSSION}

Degradation Mechanisms. The HERFD-XANES results (Figures 4 and 5) indicate that less $\mathrm{Pt} / \mathrm{C}$ oxidation occurs in the base than in the acid. The reduced amount of oxidation in the base is caused by a larger nanoparticle size at a high $\mathrm{pH}$. The HERFD-XANES results are therefore consistent with the complementary TEM results (Figure 3), which reveal that markedly more nanoparticle degradation occurs in the base. Notably, in situ spectroscopy captures minute chemical changes on the surface of Pt nanoparticles, showing the early formation of oxides in the base. Ultimately, both XAS and TEM demonstrate base-enhanced $\mathrm{Pt} / \mathrm{C}$ degradation.

In discussing base-enhanced electrode degradation within the context of nanoparticle catalysts, primary and secondary degradation are distinguished. ${ }^{66}$ Briefly, primary degradation refers to the chemical mechanisms that cause aging, such as platinum dissolution and platinum-catalyzed carbon corrosion. In turn, these primary mechanisms drive secondary processes that change the nanoparticle morphology, such as Ostwald ripening, particle migration or agglomeration (Smoluchowski agglomeration), and nanoparticle detachment. Typically, the detection of such secondary changes can indicate which primary mechanism is predominant in the system.

Between the primary mechanisms, carbon corrosion has been suggested to cause enhanced $\mathrm{Pt} / \mathrm{C}$ degradation in base. ${ }^{26}$ Such corrosion is Pt-catalyzed ${ }^{48}$ and is hypothesized to be accelerated by hydroxide ions in base, ${ }^{26}$ as carbon corrosion could degrade the metal-support interactions and form carbon dioxide. ${ }^{48,67}$ In alkaline solutions, this carbon dioxide would precipitate as carbonate salts. Within this suggested mechanism, the physical stress caused by the formation of solid carbonates and the weakened $\mathrm{Pt}$-support bonds would cause 
the detachment of $\mathrm{Pt}$ nanoparticles. ${ }^{26}$ Once detached, $\mathrm{Pt}$ particles can diffuse into the working electrolyte, thus decreasing the nanoparticle density and the overall Pt loading on the support. ${ }^{29,30}$ Alternatively, they could undergo Smoluchowski agglomeration by migrating within the support structure and colliding with other Pt particles. ${ }^{68}$ Smoluchowski agglomeration generally causes the nanoparticle size distribution to tail toward large agglomerated particles. ${ }^{69,70}$

Smoluchowski agglomeration could also be caused by $\mathrm{Pt}$ dissolution and redeposition because $\mathrm{Pt}$ atoms dissolve from one side of a nanoparticle and are redeposited on a different side, thus causing a net migration of the particle. ${ }^{71}$ In addition, $\mathrm{Pt}$ dissolution and redeposition drives Ostwald ripening. ${ }^{68}$ Although the effects of Ostwald ripening on particle size distributions vary, ${ }^{72,73}$ there is one prominent Ostwald ripening feature: the presence of nanoparticles that are smaller than those in the initial nanoparticle ink. ${ }^{74}$ These particles form because Ostwald ripening preferentially consumes small particles, which will shrink to sizes that are not present in the initial nanoparticle size distribution. The presence of these minuscule particles is therefore an indicator of Ostwald ripening and, by extension, Pt dissolution. ${ }^{74}$

Based on the outlined degradation processes, one can set out to distinguish $\mathrm{Pt}$ dissolution and carbon corrosion. Of the secondary processes, Smoluchowski agglomeration is the most prominent secondary change in the present work. A pronounced agglomeration-induced tail is visible in the particle size distributions for both $\mathrm{pH} 2$ and $\mathrm{pH} 12$ in Figure 3, with exacerbated tailing visible in $\mathrm{pH} 12$. Similarly, large particle agglomerates are visible for the base-aged samples in Figures S3 and S4. Notably, Smoluchowski agglomeration can be caused by both $\mathrm{Pt}$ dissolution and carbon corrosion. When distinguishing these primary processes, one should therefore rely on Ostwald ripening and nanoparticle detachment, which respectively indicate $\mathrm{Pt}$ dissolution/redeposition and carbon corrosion.

The present work reveals a reduced nanoparticle density for the alkaline samples in the micrographs, as seen in Figure S3. The loss of particles points toward carbon corrosion, which is consistent with previous degradation reports. ${ }^{29,30}$ Simultaneously, TEM reveals the presence of particles with sub-1.2 nm diameters after moderate aging at $\mathrm{pH} 12$ (Figure 3b). Such small nanoparticles are not present in the initial nanoparticle ink and therefore indicate Ostwald ripening. In turn, Ostwald ripening points toward degradation through Pt dissolution/ redeposition. As such, the present TEM results support the simultaneous occurrence of $\mathrm{Pt}$ dissolution and carbon corrosion, which are enhanced in the base.

Base-Enhanced Pt-Based Degradation. The reasons for this alkaline enhancement are actively being researched for both carbon corrosion and Pt dissolution. ${ }^{24-27}$ Although the carbon corrosion mechanism is beyond the scope of this work, the present results do allow for conclusions on Pt-based degradation. Because such degradation inherently involves both the dissolution and redeposition of $\mathrm{Pt}{ }^{68,71}$ each of these components will be discussed separately.

Pt dissolution will be $\mathrm{pH}$-dependent if the stability of the oxidized Pt species is also $\mathrm{pH}$-dependent. Consequentially, different types or varying amounts of oxidized Pt species would form at different $\mathrm{pH}$ values. From an electrochemical perspective, there is only a $\sim 20 \%$ difference between oxidation and reduction charge densities between electrolytes. Importantly, this difference favors oxidation in acid and thus does not explain base-enhanced aging, which is also supported by the higher degree of oxidation in the acid above $1.0 \mathrm{~V}$ vs RHE. Analogously, HERFD-XANES reveals an earlier oxidation onset in the base than in the acid (Figures 4 and 5, respectively), but does not support a pronounced speciation difference in $\mathrm{Pt}$ oxidation at higher potentials, i.e., a $\mathrm{PtO}_{2}$-like oxide forms at both $\mathrm{pH} 2$ and $\mathrm{pH} 12$ at potentials higher than 1.2-1.4 V vs RHE. This similarity between the acid and the base is supported by the similar shapes of the difference spectra in Figure $4 \mathrm{c}$ and $\mathrm{d}$, which match the shape of hydrated $\mathrm{PtO}_{2}$ (Figure S6).

With Pt dissolution seeming similar in both the acid and the base, it appears that Pt redeposition differs between acidic and alkaline $\mathrm{Pt} / \mathrm{C}$ degradation. ${ }^{24,25,28}$ This hypothesis relies on alkaline electrolytes containing hydroxide ions, which form complexes with dissolved Pt. As a result, the dissolved Pt is stabilized in base and is more likely to diffuse prior to redeposition. ${ }^{24,25}$ Such solvated $\mathrm{Pt}$ is generally lost when bulk Pt electrodes are involved, ${ }^{24}$ but carbon-supported Pt electrodes allow for diffusion within the 3D carbon support. ${ }^{52,68,75}$ In these 3D systems, diffusion and subsequent redeposition will cause enhanced Ostwald ripening and Smoluchowski agglomeration, respectively. These effects are consistent with those observed in the present work. Similar results are obtained if $\mathrm{Pt} /$ $\mathrm{C}$ is cycled in acidic solutions, but only if complexing ions such as chloride are present. ${ }^{76}$ In the present work, only the high$\mathrm{pH}$ systems contain complexing ions in the form of $\mathrm{OH}^{-}$. These complexing ions stabilize the dissolved $\mathrm{Pt}$ species at $\mathrm{pH}$ 12, which causes base-enhanced diffusion of $\mathrm{Pt}$ species and subsequent catalyst degradation. This diffusion should be enhanced if more $\mathrm{OH}^{-}$is present, which has indeed been shown when $\mathrm{Pt}$ dissolution is compared in 0.02 and $0.2 \mathrm{M}$ $\mathrm{KOH}^{7}$

The aforementioned diffusion-promoting role of $\mathrm{OH}^{-}$is consistent with recent work that compares $\mathrm{Pt} / \mathrm{C}$ degradation in a liquid $0.1 \mathrm{M} \mathrm{NaOH}$ electrolyte and in a dry solid-polymer electrolyte. ${ }^{30}$ This comparison demonstrated reduced aging in the solid electrolyte, which was ascribed to the reduced mobility of dissolved Pt species prior to redeposition. Likewise, Pt loss from fuel cell catalysts can be reduced by impeding the mass transport of dissolved Pt species. ${ }^{52}$ Such mass transport effects can generate different nanoparticle growth regimes throughout thick catalyst layers. ${ }^{75}$ Although such spatial inhomogeneities cannot be assessed in the present study, our current results explicitly underscore the importance of the diffusion of $\mathrm{Pt}^{n+}$ that occurs between dissolution and redeposition. It is therefore crucial to look beyond the oxidation and reduction behavior of $\mathrm{Pt}$ when assessing fuel cell catalyst stability, as the diffusion of dissolved species appears to be equally relevant. Furthermore, this relevance could even vary with operational parameters such as the temperature, which is known to affect Pt catalyst degradation. ${ }^{7}$ Additionally, the type of complexing anions will likely determine the type of $\mathrm{Pt}$ complex that forms in solution. Consequently, the stability of the dissolved Pt will depend on the type of complexing anion. Determining the exact type of the dissolved $\mathrm{Pt}$ species would be a notable future research goal if solution-based spectroscopy or online chromatography and mass spectrometry techniques are optimized to distinguish the minuscule amounts of dissolved Pt.

Analysis of Aging Effects. The previous sections underscore the simultaneous occurrence of carbon corrosion and platinum dissolution while subsequently discussing base- 
enhanced Pt dissolution in light of the results presented here and in recent literature. Having done this, a final discussion will be devoted to generally summarizing $\mathrm{Pt} / \mathrm{C}$ aging in the present work.

As discussed in the Degradation Mechanisms subsection, $\mathrm{Pt} / \mathrm{C}$ aging in this work occurs through a combination of Ostwald ripening, Smoluchowski agglomeration, and $\mathrm{Pt}$ detachment. Although signs for all of these mechanisms are present, it appears that Smoluchowski agglomeration eventually dominates the aging process. This dominance is

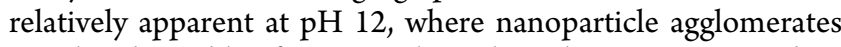
are already visible after a simple cyclic voltammetry procedure (Figure 3b). Agglomerates larger than $5 \mathrm{~nm}$ are relatively rare in $\mathrm{pH} 2$, but a positively skewed particle size distribution in Figure $3 \mathrm{a}$ also indicates the prevailing Smoluchowski agglomeration after extensive aging. ${ }^{70}$

A final scrutiny of the size distributions in Figure 3 sheds light on the relative importance of steady-state and transient dissolution. As mentioned in the Introduction, steady-state dissolution occurs during constant anodic polarization, whereas transient dissolution takes place during oxidation-reduction cycles. ${ }^{21}$ In the case of platinum, transient dissolution generally causes more Pt loss than steady-state dissolution. ${ }^{21,27}$ This behavior is parallel to alkaline aging in this work since the most dramatic Pt/C growth occurs after the $\mathrm{CV}$ treatment (Figure $3 \mathrm{~b})$. However, this behavior is unmatched by $\mathrm{Pt} / \mathrm{C}$ at $\mathrm{pH} 2$. As reported previously, ${ }^{54}$ only marginal $\mathrm{Pt} / \mathrm{C}$ growth is detectable after both the CV treatment and a subsequent $1.4 \mathrm{~V}$ hold, whereas clear particle growth is only visible in the acid after extensive aging (Figure 3a). The lack of severe $\mathrm{Pt} / \mathrm{C}$ aging after cycling might be caused by passivation effects for the small nanoparticle sizes in this work $^{7,51}$ and deserves further attention in future $\mathrm{Pt} / \mathrm{C}$ aging studies.

\section{CONCLUSIONS}

Summarizing, this work has demonstrated $\mathrm{pH}$-dependent $\mathrm{Pt} / \mathrm{C}$ aging during both cyclic voltammetry and constant anodic polarization. The results show that more $\mathrm{Pt} / \mathrm{C}$ degradation occurs in base than in acid, which is consistent with previous reports. $^{24,26,28-30}$ The details of base-accelerated degradation were rigorously probed through a combination of electrochemistry, ex situ TEM, and in situ HERFD-XANES. Our analysis indicates that catalyst aging is a result of a combination of Ostwald ripening, Smoluchowski agglomeration, and $\mathrm{Pt}$ nanoparticle detachment. In turn, these secondary processes suggest an interplay between both carbon corrosion and $\mathrm{Pt}$ dissolution/redeposition as primary degradation mechanisms. Electrochemistry revealed no signs of different oxidation mechanisms between the acid and the base, as both electrolytes produced similar $\mathrm{Pt}$ oxidation and reduction charges. Furthermore, HERFD-XANES indicated the generation of a $\mathrm{PtO}_{2}$ phase at both low and high $\mathrm{pH}$ levels at potentials larger than $1.2 \mathrm{~V}$ vs RHE. Interestingly, in situ XAS suggests a $\sim 100 \mathrm{mV}$ earlier onset for the formation of oxides of $\mathrm{Pt}$ in base. Finally, it seems that base-induced Pt complexation facilitates the diffusion of dissolved $\mathrm{Pt}$ in base. This increased stability and mobility of solution-phase Pt would contribute to the base-enhanced Ostwald ripening and Smoluchowski agglomeration upon redeposition. Importantly, this conclusion indicates that similar fundamental $\mathrm{Pt}$ oxidation and reduction processes occur in the acid and the base, but the $\mathrm{pH}$ dependent chemistry of dissolved $\mathrm{Pt}$ is the cause of the baseenhanced Pt degradation through dissolution and redeposition.
Notably, these insights on the coexistence of Pt-based degradation and carbon corrosion would not have been reached without combining ex situ and in situ catalyst characterizations and shed valuable additional light on the relatively understudied issue of base-accelerated Pt catalyst degradation. The results additionally show that electrochemistry can conceal $\mathrm{pH}$-dependent differences in $\mathrm{Pt} / \mathrm{C}$ degradation, and in situ characterizations are critical for further advances. Such an improved understanding is required to implement Pt-catalyzed alkaline electrochemical reactions in general and alkaline fuel cells specifically. The present insights therefore mark relevant progress toward achieving a functional hydrogen economy.

\section{ASSOCIATED CONTENT}

\section{Supporting Information}

The Supporting Information is available free of charge at https://pubs.acs.org/doi/10.1021/acscatal.1c02468.

Representative transmission electron micrographs, additional particle size distributions, comparison of difference spectra with those of standard compounds, and HERFD-XANES fit details (PDF)

\section{AUTHOR INFORMATION}

\section{Corresponding Authors}

Marc T. M. Koper - Leiden Institute of Chemistry, Leiden University, 2300 RA Leiden, The Netherlands; 다이.org/ 0000-0001-6777-4594; Email: m.koper@lic.leidenuniv.nl

Angel T. Garcia-Esparza - Stanford Synchrotron Radiation Lightsource, SLAC National Accelerator Laboratory, Menlo Park, California 94025, United States of America; ○ orcid.org/0000-0002-4884-171X; Email: garciaat@ slac.stanford.edu

\section{Authors}

Thomas J. P. Hersbach - Stanford Synchrotron Radiation Lightsource, SLAC National Accelerator Laboratory, Menlo Park, California 94025, United States of America; Leiden Institute of Chemistry, Leiden University, 2300 RA Leiden, The Netherlands; O orcid.org/0000-0001-5467-6151

Amanda C. Garcia - Leiden Institute of Chemistry, Leiden University, 2300 RA Leiden, The Netherlands; Present Address: Faculty of Science, Van ' $t$ Hoff Institute for Molecular Sciences, University of Amsterdam, Science Park 904, 1098 XH, Amsterdam, The Netherlands

Thomas Kroll - Stanford Synchrotron Radiation Lightsource, SLAC National Accelerator Laboratory, Menlo Park, California 94025, United States of America

Dimosthenis Sokaras - Stanford Synchrotron Radiation Lightsource, SLAC National Accelerator Laboratory, Menlo Park, California 94025, United States of America

Complete contact information is available at:

https://pubs.acs.org/10.1021/acscatal.1c02468

\section{Author Contributions}

$\nabla$ Both authors contributed equally.

\section{Notes}

The authors declare no competing financial interest.

\section{ACKNOWLEDGMENTS}

Use of the Stanford Synchrotron Radiation Lightsource, SLAC National Accelerator Laboratory, is supported by the U.S. 
Department of Energy, Office of Science, Office of Basic Energy Sciences under contract no. DE-AC02-76SF00515. Part of this work was performed at the Stanford Nano Shared Facilities (SNSF) and the Stanford Nanofabrication Facility (SNF), which are supported by the National Science Foundation under award ECCS-2026822. Part of this research used resources of the National Energy Research Scientific Computing Center (NERSC), a U.S. Department of Energy Office of Science User Facility located at Lawrence Berkeley National Laboratory and operated under contract no. DEAC02-05CH11231.

\section{REFERENCES}

(1) Noussan, M.; Raimondi, P. P.; Scita, R.; Hafner, M. The Role of Green and Blue Hydrogen in the Energy Transition-A Technological and Geopolitical Perspective. Sustainability 2021, 13 (1), 298.

(2) Brandon, N. P.; Kurban, Z. Clean Energy and the Hydrogen Economy. Philos. Trans. R. Soc., A 2017, 375 (2098), 20160400.

(3) Bockris, J. O. A Hydrogen Economy. Science (Washington, DC, U. S.) 1972, 176 (4041), 1323-1323.

(4) Guerra, O. J.; Eichman, J.; Kurtz, J.; Hodge, B.-M. Cost Competitiveness of Electrolytic Hydrogen. Joule 2019, 3 (10), 24252443.

(5) Hydrogen and Fuel Cell Technologies Office, AOP Lab Call DE-LC000L083; U.S. Department of Energy, Office of Energy Efficiency \& Renewable Energy: Washington, D.C., 2020.

(6) Borup, R. L.; Kusoglu, A.; Neyerlin, K. C.; Mukundan, R.; Ahluwalia, R. K.; Cullen, D. A.; More, K. L.; Weber, A. Z.; Myers, D. J. Recent Developments in Catalyst-Related PEM Fuel Cell Durability. Curr. Opin. Electrochem. 2020, 21, 192-200.

(7) Cherevko, S.; Kulyk, N.; Mayrhofer, K. J. J. Durability of Platinum-Based Fuel Cell Electrocatalysts: Dissolution of Bulk and Nanoscale Platinum. Nano Energy 2016, 29, 275-298.

(8) Aßmann, P.; Gago, A. S.; Gazdzicki, P.; Friedrich, K. A.; Wark, M. Toward Developing Accelerated Stress Tests for Proton Exchange Membrane Electrolyzers. Curr. Opin. Electrochem. 2020, 21 (March), 225-233.

(9) Saveleva, V. A.; Papaefthimiou, V.; Daletou, M. K.; Doh, W. H.; Ulhaq-Bouillet, C.; Diebold, M.; Zafeiratos, S.; Savinova, E. R. Operando Near Ambient Pressure XPS (NAP-XPS) Study of the Pt Electrochemical Oxidation in $\mathrm{H} 2 \mathrm{O}$ and $\mathrm{H} 2 \mathrm{O} / \mathrm{O} 2$ Ambients. J. Phys. Chem. C 2016, 120 (29), 15930-15940.

(10) Mom, R.; Frevel, L.; Velasco-Vélez, J.-J.; Plodinec, M.; KnopGericke, A.; Schlögl, R. The Oxidation of Platinum under Wet Conditions Observed by Electrochemical X-Ray Photoelectron Spectroscopy. J. Am. Chem. Soc. 2019, 141 (16), 6537-6544.

(11) Bucur, R. V. Structure of the Voltammograms of the PlatinumBlack Electrodes: Derivative Voltammetry and Data Fitting Analysis. Electrochim. Acta 2014, 129, 76-84.

(12) Angerstein-Kozlowska, H.; Conway, B. E.; Sharp, W. B. A. The Real Condition of Electrochemically Oxidized Platinum Surfaces. J. Electroanal. Chem. Interfacial Electrochem. 1973, 43 (1), 9-36.

(13) Tada, M.; Murata, S.; Asakoka, T.; Hiroshima, K.; Okumura, K.; Tanida, H.; Uruga, T.; Nakanishi, H.; Matsumoto, S. I.; Inada, Y.; Nomura, M.; Iwasawa, Y. In Situ Time-Resolved Dynamic Surface Events on the $\mathrm{Pt} / \mathrm{C}$ Cathode in a Fuel Cell under Operando Conditions. Angew. Chem., Int. Ed. 2007, 46 (23), 4310-4315.

(14) Imai, H.; Izumi, K.; Matsumoto, M.; Kubo, Y.; Kato, K.; Imai, Y. In Situ and Real-Time Monitoring of Oxide Growth in a Few Monolayers at Surfaces of Platinum Nanoparticles in Aqueous Media. J. Am. Chem. Soc. 2009, 131 (17), 6293-6300.

(15) Huang, Y.-F.; Kooyman, P. J.; Koper, M. T. M. Intermediate Stages of Electrochemical Oxidation of Single-Crystalline Platinum Revealed by in Situ Raman Spectroscopy. Nat. Commun. 2016, 7, 12440.

(16) Jerkiewicz, G.; Vatankhah, G.; Lessard, J.; Soriaga, M. P.; Park, Y.-S. Surface-Oxide Growth at Platinum Electrodes in Aqueous H2SO4. Electrochim. Acta 2004, 49 (9-10), 1451-1459.
(17) Shibata, S. Kinetics and Mechanism of Electrochemical Reduction of Multilayer Oxides on a Smooth Platinum Electrode Surface in Acidic Electrolyte. J. Electroanal. Chem. Interfacial Electrochem. 1978, 89 (1), 37-58.

(18) Gómez-Marín, A. M.; Feliu, J. M. Pt(111) Surface Disorder Kinetics in Perchloric Acid Solutions and the Influence of Specific Anion Adsorption. Electrochim. Acta 2012, 82, 558-569.

(19) Huang, Y.-F.; Koper, M. T. M. Electrochemical Stripping of Atomic Oxygen on Single-Crystalline Platinum: Bridging Gas-Phase and Electrochemical Oxidation. J. Phys. Chem. Lett. 2017, 8 (6), $1152-1156$.

(20) Cherevko, S.; Keeley, G. P.; Geiger, S.; Zeradjanin, A. R.; Hodnik, N.; Kulyk, N.; Mayrhofer, K. J. J. Dissolution of Platinum in the Operational Range of Fuel Cells. ChemElectroChem 2015, 2 (10), $1471-1478$

(21) Cherevko, S.; Zeradjanin, A. R.; Topalov, A. A.; Kulyk, N.; Katsounaros, I.; Mayrhofer, K. J. J. Dissolution of Noble Metals during Oxygen Evolution in Acidic Media. ChemCatChem 2014, 6 (8), 2219-2223.

(22) Pavlišič, A.; Jovanovič, P.; Šelih, V. S.; Šala, M.; Hodnik, N.; Gaberšček, M. Platinum Dissolution and Redeposition from Pt/C Fuel Cell Electrocatalyst at Potential Cycling. J. Electrochem. Soc. 2018, 165 (6), F3161-F3165.

(23) Xing, L.; Jerkiewicz, G.; Beauchemin, D. Ion Exchange Chromatography Coupled to Inductively Coupled Plasma Mass Spectrometry for the Study of Pt Electro-Dissolution. Anal. Chim. Acta 2013, 785, 16-21.

(24) Deng, X.; Galli, F.; Koper, M. T. M. In Situ AFM Imaging of Platinum Electrode Surface during Oxidation-Reduction Cycles in Alkaline Electrolyte. ACS Appl. Energy Mater. 2020, 3, 597-602.

(25) Lopes, P. P.; Strmcnik, D.; Tripkovic, D.; Connell, J. G.; Stamenkovic, V.; Markovic, N. M. Relationships between Atomic Level Surface Structure and Stability/Activity of Platinum Surface Atoms in Aqueous Environments. ACS Catal. 2016, 6 (4), 25362544.

(26) Lafforgue, C.; Zadick, A.; Dubau, L.; Maillard, F.; Chatenet, M. Selected Review of the Degradation of Pt and Pd-Based CarbonSupported Electrocatalysts for Alkaline Fuel Cells: Towards Mechanisms of Degradation. Fuel Cells 2018, 18 (3), 229-238.

(27) Cherevko, S.; Zeradjanin, A. R.; Keeley, G. P.; Mayrhofer, K. J. J. A Comparative Study on Gold and Platinum Dissolution in Acidic and Alkaline Media. J. Electrochem. Soc. 2014, 161 (12), H822-H830.

(28) Deng, X.; Galli, F.; Koper, M. T. M. In Situ Electrochemical AFM Imaging of a Pt Electrode in Sulfuric Acid under Potential Cycling Conditions. J. Am. Chem. Soc. 2018, 140 (41), 13285-13291.

(29) Zadick, A.; Dubau, L.; Sergent, N.; Berthomé, G.; Chatenet, M. Huge Instability of $\mathrm{Pt} / \mathrm{C}$ Catalysts in Alkaline Medium. ACS Catal. 2015, 5 (8), 4819-4824.

(30) Lafforgue, C.; Chatenet, M.; Dubau, L.; Dekel, D. R. Accelerated Stress Test of $\mathrm{Pt} / \mathrm{C}$ Nanoparticles in an Interface with an Anion-Exchange Membrane - An Identical-Location Transmission Electron Microscopy Study. ACS Catal. 2018, 8 (2), 1278-1286.

(31) Qureshi, M.; Garcia-Esparza, A. T.; Shinagawa, T.; Sautet, P.; Le Bahers, T.; Takanabe, K. Contribution of Electrolyte in Nanoscale Electrolysis of Pure and Buffered Water by Particulate Photocatalysis. Sustain. Energy Fuels 2018, 2 (9), 2044-2052.

(32) Shinagawa, T.; Garcia-Esparza, A. T.; Takanabe, K. Mechanistic Switching by Hydronium Ion Activity for Hydrogen Evolution and Oxidation over Polycrystalline Platinum Disk and Platinum/Carbon Electrodes. ChemElectroChem 2014, 1 (9), 1497-1507.

(33) Vidal-Iglesias, F. J.; Arán-Ais, R. M.; Solla-Gullón, J.; Herrero, E.; Feliu, J. M. Electrochemical Characterization of Shape-Controlled Pt Nanoparticles in Different Supporting Electrolytes. ACS Catal. 2012, 2 (5), 901-910.

(34) Garcia-Esparza, A. T.; Shinagawa, T.; Ould-Chikh, S.; Qureshi, M.; Peng, X.; Wei, N.; Anjum, D. H.; Clo, A.; Weng, T.-C.; Nordlund, D.; Sokaras, D.; Kubota, J.; Domen, K.; Takanabe, K. An OxygenInsensitive Hydrogen Evolution Catalyst Coated by a Molybdenum- 
Based Layer for Overall Water Splitting. Angew. Chem., Int. Ed. 2017, 56 (21), 5780-5784.

(35) Sokaras, D.; Weng, T.-C.; Nordlund, D.; Alonso-Mori, R.; Velikov, P.; Wenger, D.; Garachtchenko, A.; George, M.; Borzenets, V.; Johnson, B.; Rabedeau, T.; Bergmann, U. A Seven-Crystal JohannType Hard $\mathrm{x}$-Ray Spectrometer at the Stanford Synchrotron Radiation Lightsource. Rev. Sci. Instrum. 2013, 84 (5), No. 053102.

(36) Bauer, M. HERFD-XAS and Valence-to-Core-XES: New Tools to Push the Limits in Research with Hard X-Rays? Phys. Chem. Chem. Phys. 2014, 16 (27), 13827-13837.

(37) Ravel, B.; Newville, M. ATHENA, ARTEMIS, HEPHAESTUSData Analysis for X-Ray Absorption Spectroscopy Using IFEFFIT. J. Synchrotron Radiat. 2005, 12 (4), 537-541.

(38) Calvin, S. XAFS for Everyone, 1st ed.; CRC Press: Boca Raton, FL, 2013. DOI: $10.1007 / \mathrm{s} 13398-014-0173-7.2$.

(39) Attard, G. A.; Brew, A.; Hunter, K.; Sharman, J.; Wright, E. Specific Adsorption of Perchlorate Anions on Pt $\{\mathrm{hkl}\}$ Single Crystal Electrodes. Phys. Chem. Chem. Phys. 2014, 16 (27), 13689-13698.

(40) Chen, X.; McCrum, I. T.; Schwarz, K. A.; Janik, M. J.; Koper, M. T. M. Co-Adsorption of Cations as the Cause of the Apparent PH Dependence of Hydrogen Adsorption on a Stepped Platinum SingleCrystal Electrode. Angew. Chem., Int. Ed. 2017, 56 (47), 1502515029.

(41) McCrum, I. T.; Chen, X.; Schwarz, K. A.; Janik, M. J.; Koper, M. T. M. Effect of Step Density and Orientation on the Apparent PH Dependence of Hydrogen and Hydroxide Adsorption on Stepped Platinum Surfaces. J. Phys. Chem. C 2018, 122 (29), 16756-16764.

(42) Jiao, L.; Liu, E.; Mukerjee, S.; Jia, Q. In Situ Identification of Non-Specific Adsorption of Alkali Metal Cations on Pt Surfaces and Their Catalytic Roles in Alkaline Solutions. ACS Catal. 2020, 10 (19), 11099-11109.

(43) Park, Y. C.; Kakinuma, K.; Uchida, M.; Uchida, H.; Watanabe, M. Deleterious Effects of Interim Cyclic Voltammetry on Pt/Carbon Black Catalyst Degradation during Start-up/Shutdown Cycling Evaluation. Electrochim. Acta 2014, 123, 84-92.

(44) Gribov, E. N.; Maltseva, N. V.; Golovin, V. A.; Okunev, A. G. A Simple Method for Estimating the Electrochemical Stability of the Carbon Materials. Int. J. Hydrogen Energy 2016, 41 (40), 1820718213.

(45) Sasaki, K.; Marinkovic, N.; Isaacs, H. S.; Adzic, R. R. Synchrotron-Based In Situ Characterization of Carbon-Supported Platinum and Platinum Monolayer Electrocatalysts. ACS Catal. 2016, $6(1), 69-76$

(46) Tremiliosi-Filho, G.; Jerkiewicz, G.; Conway, B. E. Characterization and Significance of the Sequence of Stages of Oxide Film Formation at Platinum Generated by Strong Anodic Polarization. Langmuir 1992, 8 (2), 658-667.

(47) Chen, D.; Tao, Q.; Liao, L. W.; Liu, S. X.; Chen, Y. X.; Ye, S. Determining the Active Surface Area for Various Platinum Electrodes. Electrocatalysis 2011, 2 (3), 207-219.

(48) Pizzutilo, E.; Geiger, S.; Grote, J.-P.; Mingers, A.; Mayrhofer, K. J. J.; Arenz, M.; Cherevko, S. On the Need of Improved Accelerated Degradation Protocols (ADPs): Examination of Platinum Dissolution and Carbon Corrosion in Half-Cell Tests. J. Electrochem. Soc. 2016, 163 (14), F1510-F1514.

(49) Schonvogel, D.; Hülstede, J.; Wagner, P.; Dyck, A.; Agert, C.; Wark, M. Investigation of Reduced Graphene Oxide with F-Doped SnOi as Catalyst Support in Fuel Cells. ECS Trans. 2017, 80 (8), 879-895.

(50) Zhou, Y.-W.; Chen, Y.-F.; Jiang, K.; Liu, Z.; Mao, Z.-J.; Zhang, W.-Y.; Lin, W.-F.; Cai, W.-B. Probing the Enhanced Methanol Electrooxidation Mechanism on Platinum-Metal Oxide Catalyst. Appl. Catal., B 2021, 280, 119393.

(51) Sandbeck, D. J. S.; Secher, N. M.; Speck, F. D.; Sørensen, J. E.; Kibsgaard, J.; Chorkendorff, I.; Cherevko, S. Particle Size Effect on Platinum Dissolution: Considerations for Accelerated Stability Testing of Fuel Cell Catalysts. ACS Catal. 2020, 10 (11), 6281-6290.

(52) Ehelebe, K.; Knöppel, J.; Bierling, M.; Mayerhöfer, B.; Böhm, T.; Kulyk, N.; Thiele, S.; Mayrhofer, K. J. J.; Cherevko, S. Platinum
Dissolution in Realistic Fuel Cell Catalyst Layers. Angew. Chem., Int. Ed. 2021, 60 (16), 8882-8888.

(53) Merte, L. R.; Behafarid, F.; Miller, D. J.; Friebel, D.; Cho, S.; Mbuga, F.; Sokaras, D.; Alonso-Mori, R.; Weng, T.-C.; Nordlund, D.; Nilsson, A.; Roldan Cuenya, B. Electrochemical Oxidation of SizeSelected Pt Nanoparticles Studied Using in Situ High-EnergyResolution X-Ray Absorption Spectroscopy. ACS Catal. 2012, 2 (11), 2371-2376.

(54) Myers, D. J.; Wang, X.; Smith, M. C.; More, K. L. Potentiostatic and Potential Cycling Dissolution of Polycrystalline Platinum and Platinum Nano-Particle Fuel Cell Catalysts. J. Electrochem. Soc. 2018, 165 (6), F3178-F3190.

(55) Ramaker, D. E.; Koningsberger, D. C. The Atomic AXAFS and $\Delta \mu$ XANES Techniques as Applied to Heterogeneous Catalysis and Electrocatalysis. Phys. Chem. Chem. Phys. 2010, 12 (21), 5514.

(56) Teliska, M.; O'Grady, W. E.; Ramaker, D. E. Determination of $\mathrm{H}$ Adsorption Sites on Pt/C Electrodes in HClO 4 from Pt L 23 XRay Absorption Spectroscopy. J. Phys. Chem. B 2004, 108 (7), 23332344.

(57) Teliska, M.; O'Grady, W. E.; Ramaker, D. E. Determination of $\mathrm{O}$ and $\mathrm{OH}$ Adsorption Sites and Coverage in Situ on Pt Electrodes from Pt L 23 X-Ray Absorption Spectroscopy. J. Phys. Chem. B 2005, 109 (16), 8076-8084.

(58) Melke, J.; Schoekel, A.; Dixon, D.; Cremers, C.; Ramaker, D. E.; Roth, C. Ethanol Oxidation on Carbon-Supported Pt, PtRu, and PtSn Catalysts Studied by Operando X-Ray Absorption Spectroscopy. J. Phys. Chem. C 2010, 114 (13), 5914-5925.

(59) Kusano, S.; Matsumura, D.; Ishii, K.; Tanaka, H.; Mizuki, J. Electrochemical Adsorption on Pt Nanoparticles in Alkaline Solution Observed Using In Situ High Energy Resolution X-Ray Absorption Spectroscopy. Nanomaterials 2019, 9 (4), 642.

(60) McCrum, I. T.; Hickner, M. A.; Janik, M. J. First-Principles Calculation of Pt Surface Energies in an Electrochemical Environment: Thermodynamic Driving Forces for Surface Faceting and Nanoparticle Reconstruction. Langmuir 2017, 33 (28), 7043-7052.

(61) Friebel, D.; Viswanathan, V.; Miller, D. J.; Anniyev, T.; Ogasawara, H.; Larsen, A. H.; O'Grady, C. P.; Nørskov, J. K.; Nilsson, A. Balance of Nanostructure and Bimetallic Interactions in Pt Model Fuel Cell Catalysts: In Situ XAS and DFT Study. J. Am. Chem. Soc. 2012, 134 (23), 9664-9671.

(62) Samant, M. G.; Boudart, M. Support Effects on Electronic Structure of Platinum Clusters in Y Zeolite. J. Phys. Chem. 1991, 95 (10), 4070-4074.

(63) Mukerjee, S.; McBreen, J. Hydrogen Electrocatalysis by Carbon Supported Pt and Pt Alloys: An In Situ X-Ray Absorption Study. J. Electrochem. Soc. 1996, 143 (7), 2285.

(64) Russell, A. E.; Rose, A. X-Ray Absorption Spectroscopy of Low Temperature Fuel Cell Catalysts. Chem. Rev. 2004, 104 (10), 46134636.

(65) Chen, J.; Finfrock, Y. Z.; Wang, Z.; Sham, T. High Energy Resolution Fluorescence Detection of the Pt L 3,2 -Edge Whitelines of Pt-Based Bimetallic Systems: Implications for the Pt 5d 5/2,3/2 Density of States. J. Phys. Chem. C 2021, 125, 2327.

(66) Cherevko, S. Stability and Dissolution of Electrocatalysts: Building the Bridge between Model and "Real World" Systems. Curr. Opin. Electrochem. 2018, 8, 118-125.

(67) Möller, S.; Barwe, S.; Masa, J.; Wintrich, D.; Seisel, S.; Baltruschat, H.; Schuhmann, W. Online Monitoring of Electrochemical Carbon Corrosion in Alkaline Electrolytes by Differential Electrochemical Mass Spectrometry. Angew. Chem., Int. Ed. 2020, 59 (4), $1585-1589$.

(68) Shao-Horn, Y.; Sheng, W. C.; Chen, S.; Ferreira, P. J.; Holby, E. F.; Morgan, D. Instability of Supported Platinum Nanoparticles in Low-Temperature Fuel Cells. Top. Catal. 2007, 46 (3-4), 285-305.

(69) Zhai, Y.; Zhang, H.; Xing, D.; Shao, Z. G. The Stability of Pt/C Catalyst in H3PO4/PBI PEMFC during High Temperature Life Test. J. Power Sources 2007, 164 (1), 126-133.

(70) Kregar, A.; Kravos, A.; Katrašnik, T. Methodology for Evaluation of Contributions of Ostwald Ripening and Particle 
Agglomeration to Growth of Catalyst Particles in PEM Fuel Cells. Fuel Cells 2020, 20 (4), 487-498.

(71) Hansen, T. W.; Delariva, A. T.; Challa, S. R.; Datye, A. K. Sintering of Catalytic Nanoparticles: Particle Migration or Ostwald Ripening? Acc. Chem. Res. 2013, 46 (8), 1720-1730.

(72) Challa, S. R.; Delariva, A. T.; Hansen, T. W.; Helveg, S.; Sehested, J.; Hansen, P. L.; Garzon, F.; Datye, A. K. Relating Rates of Catalyst Sintering to the Disappearance of Individual Nanoparticles during Ostwald Ripening. J. Am. Chem. Soc. 2011, 133 (51), 2067220675.

(73) Woehl, T. J.; Park, C.; Evans, J. E.; Arslan, I.; Ristenpart, W. D.; Browning, N. D. Direct Observation of Aggregative Nanoparticle Growth: Kinetic Modeling of the Size Distribution and Growth Rate. Nano Lett. 2014, 14 (1), 373-378.

(74) Pattadar, D. K.; Zamborini, F. P. Effect of Size, Coverage, and Dispersity on the Potential-Controlled Ostwald Ripening of Metal Nanoparticles. Langmuir 2019, 35 (50), 16416-16426.

(75) Hodnik, N.; Zorko, M.; Jozinović, B.; Bele, M.; Dražič, G.; Hočevar, S.; Gaberšček, M. Severe Accelerated Degradation of PEMFC Platinum Catalyst: A Thin Film IL-SEM Study. Electrochem. Commun. 2013, 30, 75-78.

(76) Capelo, A.; Esteves, M. A.; de Sá, A. I.; Silva, R. A.; Cangueiro, L.; Almeida, A.; Vilar, R.; Rangel, C. M. Stability and Durability under Potential Cycling of $\mathrm{Pt} / \mathrm{C}$ Catalyst with New Surface-Functionalized Carbon Support. Int. J. Hydrogen Energy 2016, 41 (30), 1296212975.

(77) Wang, Z.; Tada, E.; Nishikata, A. Communication-Platinum Dissolution in Alkaline Electrolytes. J. Electrochem. Soc. 2016, 163 (14), C853-C855. 